\title{
Structure of Zinc Coating on Steels Formed by Diffusion Saturation in Nitrogen-Containing Atmosphere
}

\author{
Larisa Petrova ${ }^{1,}$, Peter Demin ${ }^{1}$, Galina Timofeeva ${ }^{2}$, and Khushnuda Sharifhodgaeva ${ }^{3}$ \\ ${ }^{1}$ MADI University, Technology of structural materials department, 125319 Leningradskiy prospect 64 \\ Moscow, Russia \\ ${ }^{2}$ MADI University, Physics department, 125319 Leningradskiy prospect 64 Moscow, Russia \\ ${ }^{3}$ Tashkent State Transport University, Material science and mechanical engineering department, \\ 100167 Tashkent Temeryurchilar 1, Uzbekistan
}

\begin{abstract}
Diffusion technique of metallization is applied for receiving of zinc coatings on low-carbon steel with transitional zone. Structure of diffusion zinc layers after saturation of $09 \mathrm{Mn} 2 \mathrm{Si}$ steel in ammonia at different temperatures is examined. Effects on saturation temperature on thickness of diffusion layers are discovered. Process at $600^{\circ} \mathrm{C}$ forms diffusion layers with high strengthening level and with smooth microhardness profiles. Elements $(\mathrm{Fe}, \mathrm{Zn}, \mathrm{N})$ spectrums are analyzed, and phase composition of zinc coating and of transitional zone is determined.
\end{abstract}

\section{Introduction}

Zinc coatings are widely used for corrosion protection of steel components and constructions working in hard climatic conditions. Corrosion damage is the main factor of reduced service life of bridge constructions elements made of low-carbon steels. For increase of such parts reliability, protective coatings are applied. In particularly zinc coatings are effective for steel corrosion protection [1-3].

There is a number of techniques for zinc coatings deposition. Diffusion metallization methods are most in demand as they allow receiving gradient structure of the layer providing good adhesion of a coating with steel substrate [4-5]. As it was examined before, nitriding of zinc coatings not only improves their adhesion but also enforces strengthening and increases wear resistance [6]. Thus zinc diffusion metallization in nitrogen-containing atmosphere may be the way to enhance the properties of steel surface providing protective layers resistant against ware and corrosion.

The purpose of this paper consists in study of structure and phase composition of zinc diffusion layers obtained in low-carbon steels in active ammonia atmosphere.

\footnotetext{
*Corresponding author: petrova_madi@mail.ru
} 


\section{Methods of experimental study}

Diffusion metallization with zinc was conducted for $09 \mathrm{Mn} 2 \mathrm{Si}$ steel by thermo-chemical treatment of specimens covered by zinc-containing suspension. In addition to zinc powder $(20 \%)$ the suspension contained quartz sand $(75 \%)$ as a filler, $\mathrm{NH}_{4} \mathrm{Cl}$ as an agent, and a binder. Specimens were saturated in ammonia atmosphere at temperatures $600 \ldots 1000^{\circ} \mathrm{C}$ during $1 . . .4$ hours.

Metallographic examinations were made in AXIOVERT 25CA optical microscope; microhardness of the layers was measured by PMT-3 tester. Methods of scanning electron microscopy (JEOL JSM-6610LV) and Auger electron spectroscopy (PHI-680) were used to study of structure and composition of diffusion layers.

\section{Results and discussion}

Thickness of obtained diffusion coatings and their structure depends on the process time and temperature. Diffusion saturation during 1 hour at $800^{\circ} \mathrm{C}$ forms metallographically observed layer of $30 \mu \mathrm{m}$ thickness (Fig. 1 a). Prolongation of the process duration up to 4 hours increases the thickness of the layer until $70 \mu \mathrm{m}$ (Fig. $1 \mathrm{~b}$ ). Saturation at temperature $1000{ }^{\circ} \mathrm{C}$ forms in 1 hour a layer of $50 \mu \mathrm{m}$ thickness (Fig. $1 \mathrm{c}$ ). A coating of the same thickness grows up during 4-hours saturation at $600^{\circ} \mathrm{C}$ (Fig. $1 \mathrm{~d}$ ). After the saturation at this temperature, a sublayer (transitional zone) is observed under the zinc coating: the total thickness of the layer increases up to $110 \ldots 120 \mu \mathrm{m}$.

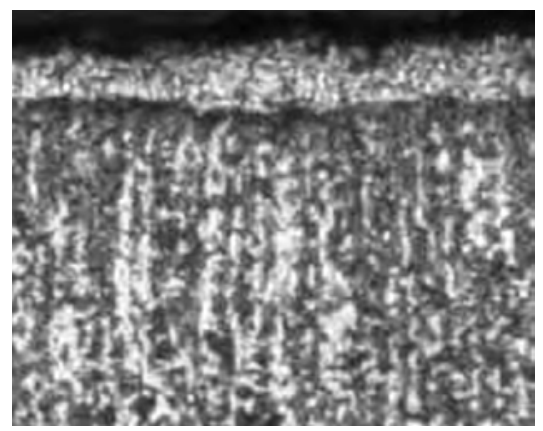

a)

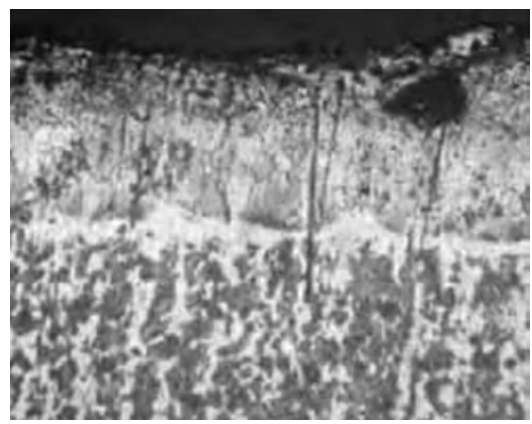

b
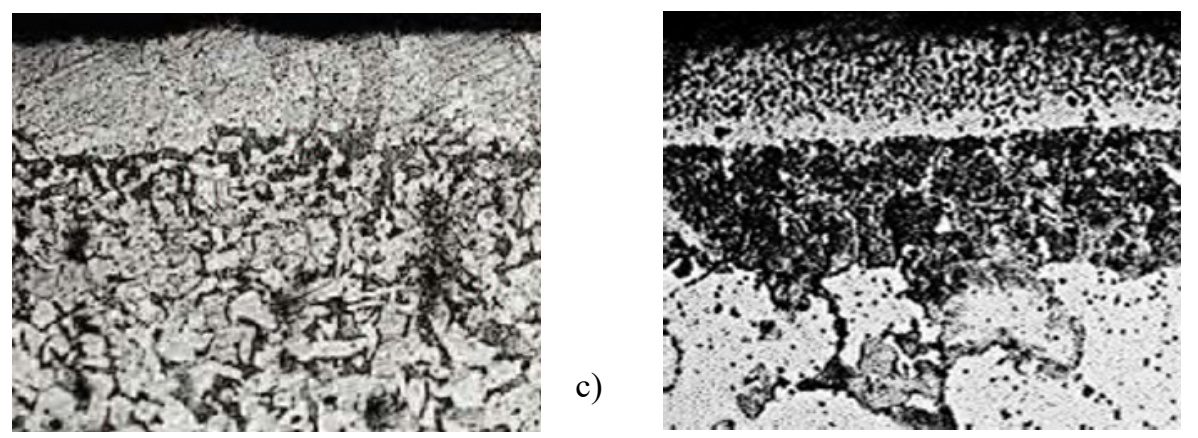

Fig. 1. Micrographs of zinc diffusion coatings received at different process regimes: a) $800^{\circ} \mathrm{C}, 1$ hour, b) $800^{\circ} \mathrm{C}, 4$ hours, c) $1000^{\circ} \mathrm{C}, 1$ hour, d) $600^{\circ} \mathrm{C}, 4$ hours

Due to the formation of the transitional zone, microhardness profile becomes smooth between coating and steel base (curve 1 at Fig. 2). At well as processes at higher temperatures forming coatings without transitional zone have sharp microhardness gradient and less level 
of strengthening (curve 2 at Fig. 2).

SEM examination shows that the surface of a zinc coating is not uniform (Fig. 3). Fragments identified as $\mathrm{ZnO}$ oxide (point Spectrum 1 with the proportion 49.7 at.\% $\mathrm{Zn}+50.3$ at.\% O) alternate spots containing $\mathrm{Zn}_{3} \mathrm{~N}_{2}$ nitride (point Spectrum 2 with $29.4 \%$ at. $\mathrm{N}$ ).

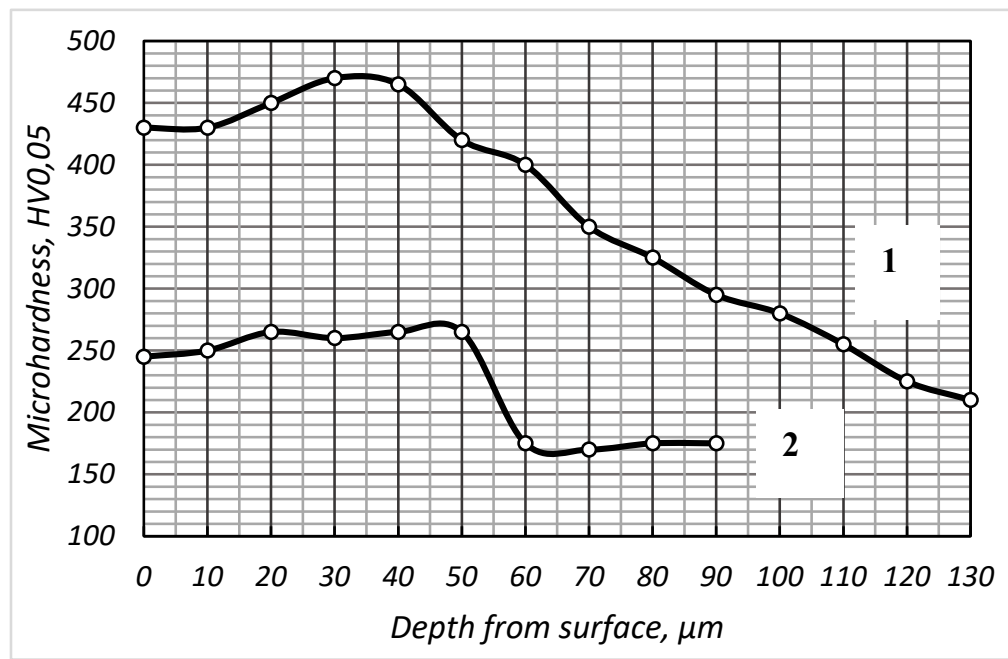

Fig. 2. Microhardness profiles of $09 \mathrm{Mn} 2 \mathrm{Si}$ steel specimens after zinc diffusion metallization at $600^{\circ} \mathrm{C}, 4$ hours (1) and at $1000^{\circ} \mathrm{C}, 1$ hour (2)
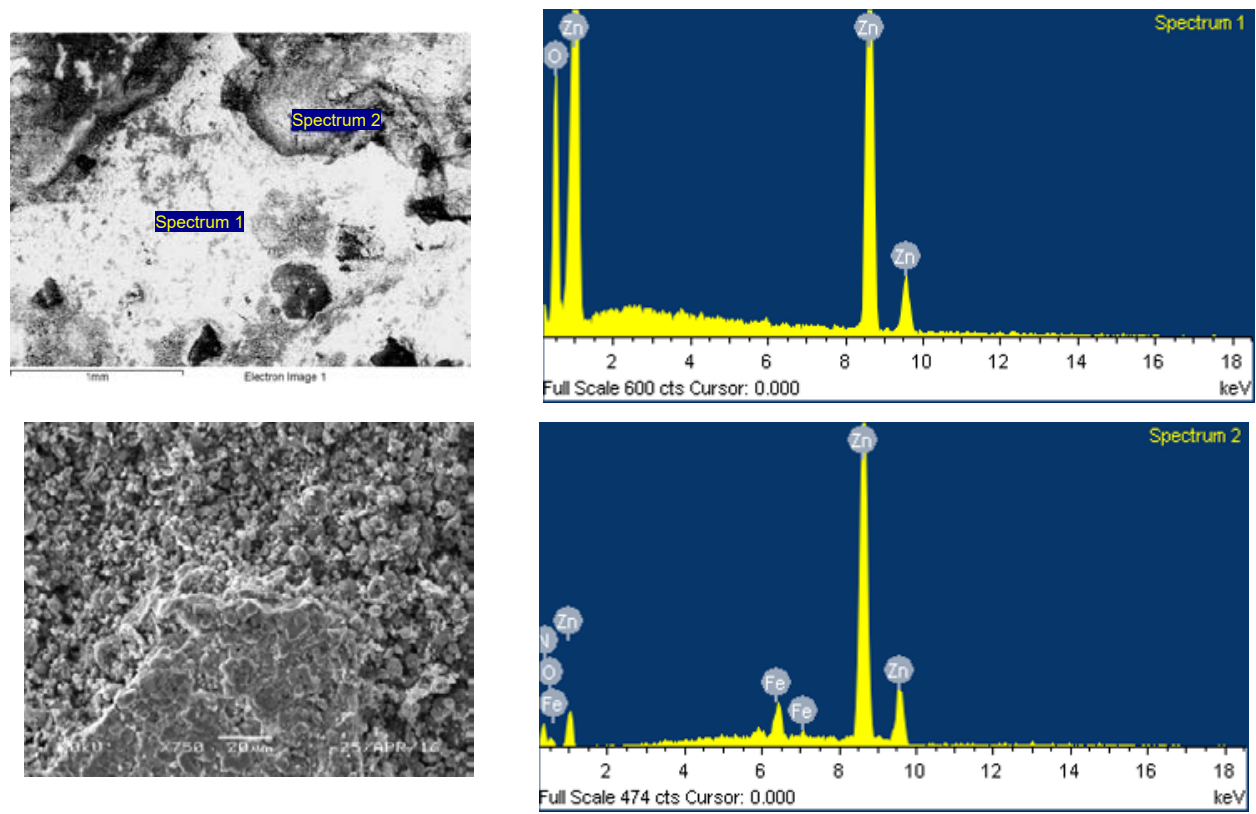

Fig. 3. SEM images of zinc coating surface and elements spectrums at points 1 and 2

For study of elements concentration changes along the diffusion layer, spectrums were quantitatively analyzed at different points remoted from a starting point $(12 \ldots 15 \mu \mathrm{m}$ below the surface). Using $\mathrm{Fe}-\mathrm{Zn}$ phase diagram, possible phases (intermetallic compounds and 
solid solutions) were determined in these points based on the $\mathrm{Fe} / \mathrm{Zn}$ concentrations ratio (Table 1).

Table 1. Chemical and phase compositions of zinc diffusion layer in control points by depth from surface

\begin{tabular}{|l|l|l|l|l|l|}
\hline \multirow{2}{*}{$\begin{array}{l}\text { Depth from starting } \\
\text { point, } \mu \mathrm{mm}\end{array}$} & \multicolumn{4}{|l|}{ Elements concentration, weight \% } & \multirow{2}{*}{ Phases } \\
\cline { 2 - 5 } & $\mathrm{Zn}$ & $\mathrm{Fe}$ & $\mathrm{Si}$ & $\mathrm{Mn}$ & \\
\hline 0 & 92.46 & 4.94 & 1,0 & 1.60 & $\delta$-FeZn \\
\hline 4.0 & 89.62 & 8.90 & - & 1.48 & $\delta$-FeZn \\
\hline 5.8 & 79.24 & 19.08 & - & 1.68 & $\Gamma-\mathrm{Fe}_{3} \mathrm{Zn}_{10}$ \\
\hline 8.90 & 40.50 & 57.88 & 1.29 & 1.62 & $\begin{array}{l}\mathrm{Fe}_{\alpha}(\mathrm{Zn})+ \\
\Gamma\end{array}$ \\
\hline 13.12 & 28.33 & 69.52 & 0.78 & 1.36 & $\begin{array}{l}\mathrm{Fe}_{\alpha}(\mathrm{Zn})+ \\
\Gamma\end{array}$ \\
\hline 16.91 & 26.98 & 71.74 & - & - & $\begin{array}{l}\mathrm{Fe}_{\alpha}(\mathrm{Zn})+ \\
\Gamma\end{array}$ \\
\hline 20.02 & 20.46 & 77.13 & 1.32 & 1.09 & $\begin{array}{l}\mathrm{Fe}_{\alpha}(\mathrm{Zn})+ \\
\Gamma\end{array}$ \\
\hline 25.81 & 21.50 & 76.87 & 0.71 & 0.92 & $\begin{array}{l}\mathrm{Fe}_{\alpha}(\mathrm{Zn})+ \\
\Gamma\end{array}$ \\
\hline 28.92 & 18.56 & 79.50 & 0.84 & 1.10 & $\mathrm{Fe}_{\alpha}(\mathrm{Zn})$ \\
\hline 35.60 & 18.75 & 78.90 & 1.15 & 1,2 & $\mathrm{Fe}_{\alpha}(\mathrm{Zn})$ \\
\hline 39.60 & 15.11 & 82.01 & 0.95 & 1.93 & $\mathrm{Fe}_{\alpha}(\mathrm{Zn})$ \\
\hline 43.61 & 3.43 & 94.28 & 0.89 & 1.40 & $\mathrm{Fe}_{\alpha}(\mathrm{Zn})$ \\
\hline 48,50 & 1.12 & 96.61 & 0.87 & 1.40 & $\mathrm{Fe}_{\alpha}(\mathrm{Zn})$ \\
\hline 53.40 & 0.00 & 97.67 & 0.85 & 1.48 & $\mathrm{Base}^{-} \mathrm{Fe}{ }_{\alpha}$ \\
\hline 59.80 & 0.00 & 97.49 & 0.82 & 1.69 & $\mathrm{Base}^{-} \mathrm{Fe}{ }_{\alpha}$ \\
\hline
\end{tabular}

Analysis shows that directly below the surface hexagonal $\delta$-phase $\mathrm{FeZn}_{7}(88.5 \ldots 93$ weight $\% \mathrm{Zn}$ ) is formed with a thin layer of $\mathrm{BCC} \Gamma$ (gamma)-phase $\mathrm{Fe}_{3} \mathrm{Zn}_{10}(72 \ldots 79$ weight $\% \mathrm{Zn})$ under it. At a greater depth a thick double-phase area of $\mathrm{Fe}_{\alpha}(\mathrm{Zn})+\Gamma$ is supposed with smooth zinc concentration decrease. A fragment of the layer with zinc concentration less than $20 \% \mathrm{Zn}$ corresponds to single-phase area of zinc solid solution in ferrite $\mathrm{Fe}_{\alpha}(\mathrm{Zn})$. This layer of $20 \mu \mathrm{m}$ thickness was determined as a part of transitional zone formed as the result of zinc diffusion penetration into iron. In deeper points, elements concentrations corresponds to the chemical composition of the basic steel.

Examination of coatings by Auger-spectroscopy discovered increased nitrogen concentration (up to 10.8 at.\% N) directly at the interface between the coating and the transitional zone. Nitrogen concentration gradually decreases in the transitional zone; concentration profiles shows that nitrogen excess concentration remains at higher depth than zinc concentration (Fig. 4). Thus the structure of the transitional zone may be described consisting of two sequential plots of solid solutions: $\mathrm{Fe}_{\alpha}(\mathrm{Zn}, \mathrm{N})$ and $\mathrm{Fe}_{\alpha}(\mathrm{N})$. 


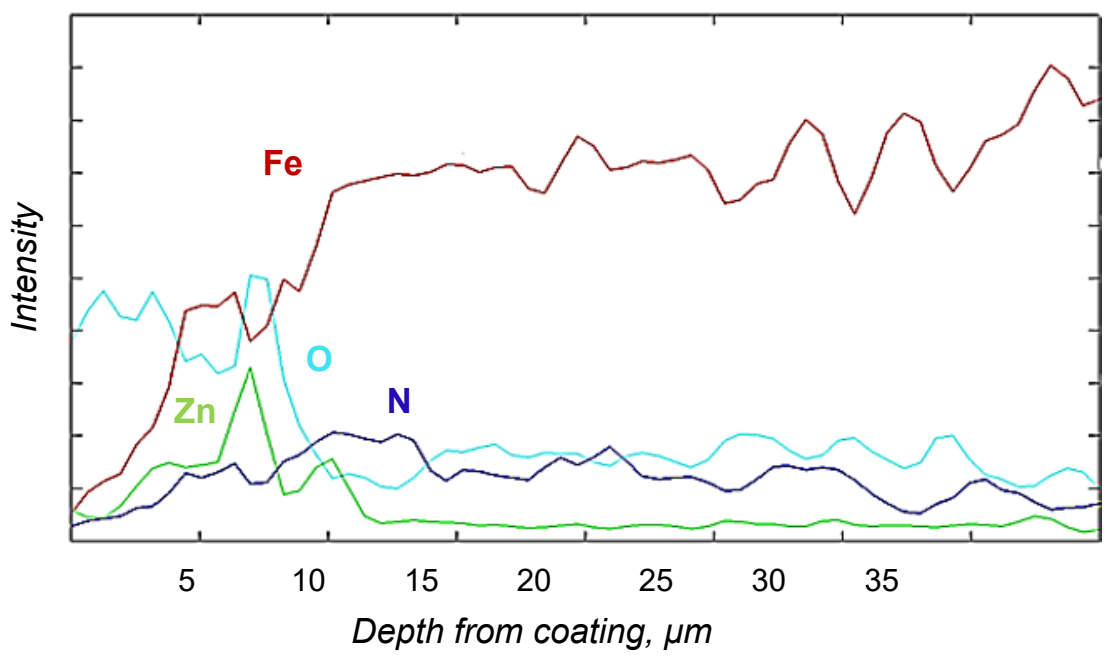

Fig. 4. Auger-profiles of elements in transitional zone under zinc coating

\section{Conclusion}

Saturation of low-carbon steel samples covered by zinc-containing suspension in ammonia allows forming a multiphase diffusion layer that composed of zinc coating and of transitional zone. Zinc coating has $\mathrm{ZnO}$ oxide and $\mathrm{Zn}_{3} \mathrm{~N}_{2}$ nitrides at the surface and consequently precipitated intermetallic compounds $\left(\delta-\mathrm{FeZn}_{7}\right.$ and $\left.\Gamma-\mathrm{Fe}_{3} \mathrm{Zn}_{10}\right)$. The thickness of coatings and achieved microhardness depends on the process temperature. After saturation at $600^{\circ} \mathrm{C}$, parallel nitriding occurs, and strengthened transitional zone is formed with smoothly decreased microhardness by the depth. The transitional zone has the structure of solid solution $\mathrm{Fe}_{\alpha}(\mathrm{Zn}, \mathrm{N}) \rightarrow \mathrm{Fe}_{\alpha}(\mathrm{N})$. Elevated microhardness of the transitional zone comparing to microharness of steel base is the consequence of solid solution strengthening of ferrite by dissolved nitrogen.

The material was prepared within the framework of scientific research under the project №FSFM-20200011 (2019-1342); experimental studies were carried out using the equipment of the MADI Centre of collective usage.

\section{References}

1. N.G. Anufriev, N.E. Smirnova, S.V. Oleynik, Corrosion, materials, protection, 2 (2003)

2. O.Y. Subbotina, O.V. Yaroslavceva, Industrial painting, 1 (2007)

3. A.S. Astalukhina, E.S. Pikalov, Successes of modern natural science, 11, 1 (2015)

4. L.G. Petrova, P.E. Demin, A.V. Kosachev, S.I. Barabanov, Polymer Science. Series D, 10, 2 (2017)

5. V.M. Gusev, V.B. Mordynskiy, M.G. Frolova, Steel, 1 (2015)

6. L.G. Petrova, P.E. Demin, G.Y. Timofeeva, A.V. Kosachev, S.I. Barabanov, V.D. Aleksandrov, Russian Engineering Research, 39, 8 (2019) 